\title{
Acute effects of lobectomy on right ventricular ejection fraction and mixed venous oxygen saturation
}

Nabil A. Mageed, ${ }^{*}$ Yasser A. Farag El-Ghonaimy, † Mohamed-Adel F. Elgamal,† Usama Hamza†

BACKGROUND: Traditional methods of assessing the operative risk for lung resection provide only a modest ability to predict postoperative morbidity and mortality. The aim of this study was to evaluate the effect of lobectomy on pulmonary hemodynamic and gas exchange variables using the RV thermodilution ejection fraction/oximetric catheter. METHODS: We evaluated the acute postoperative effects of lung resection on hemodynamic and gas exchange parameters in 30 patients. Anesthesia was induced with thiopentone sodium and maintained with midazolam, fentanyl and pipecuronium. Intubation was performed with a double-lumen, left-sided endobronchial tube for one lung ventilation. The hemodynamic and gas exchange parameters were recorded before and after induction of anesthesia, and two hours after lung resection. These parameters were also recorded after the classification of the patients according to the underlying lung pathology.

RESULTS: Lobectomy was associated with significant hemodynamic changes and good maintenance of gas exchange variables. SVI, LVSWI and RVEF were significantly decreased in the early postoperative period after lung resection. MPAP, COP, CI, SVRI, PVRI, RVSWI, and RVEDVI showed no significant changes during the perioperative period. $\mathrm{SVO}_{2}$ showed a significant increase after lung resection when compared with preinduction values, while $\mathrm{VO}_{2}$ significantly decreased. $\mathrm{SaO}_{2}$, a- $\mathrm{A} \mathrm{PO}_{2}$, $\mathrm{QS}-\mathrm{QT}, \mathrm{DO}_{2}$, and $\mathrm{O}_{2} \mathrm{ER}$ showed no significant changes during the perioperative period.

CONCLUSIONS: We conclude that in the acute post-resection period (up to 2 hours postoperatively) there is right and left ventricular dysfunction with good maintenance of gas exchange.
From Mansoura University, *Department of Anesthesiology, +Cardiovascular Surgery,

Dakabliah, Egypt

Correspondence:

Mohamed-Adel F. Elgamal, MD

Mansoura University

Department of

Cardiothoracic Surgery

El Gomboriah Street Mansour

Dakaliah 35516

Egypt

adelelgamal@yahoo.com

Accepted for publication

May 2005

Ann Saudi Med 2005;25(6):481-485
$\mathrm{L}$ ung resection results in loss of lung parenchyma. The functional loss resulting from pulmonary resection varies with the extent of resection, the relative function of the tissue removed compared with that remaining, and the degree of baseline disease. The major determinant of postoperative morbidity and mortality after pulmonary resection is the functional status of the cardiac and pulmonary systems. Traditional methods of assessing the operative risk of lung resection have provided only a modest ability to predict postoperative morbidity and mortality. ${ }^{1,2}$ Previous studies yielded conflicting results on the use of preoperative pulmonary function testing as a predicator of postoperative complications. ${ }^{3,4}$ The development of the right ventricular (RV) thermodilution ejection fraction/oximetric catheter has allowed assessment of RV performance in a variety of conditions including shock, ${ }^{5}$ sepsis, ${ }^{5}$ thermal injury. ${ }^{6}$ and after coronary bypass grafting. ${ }^{7}$

Four studies investigating RV function using thermodilution dem- 


\begin{tabular}{|c|c|}
\hline $\begin{array}{l}\mathrm{a} / \mathrm{APO}_{2} \\
\mathrm{Cl}\end{array}$ & $\begin{array}{l}\text { Arterial-alveolar oxygen tension ratio } \\
\text { Cardiac index }\end{array}$ \\
\hline $\mathrm{CO}$ & Cardiac output \\
\hline COP & Coronary oxygen persufflation \\
\hline CVP & Central venous pressure \\
\hline CVP & Central venous pressure \\
\hline $\mathrm{DO}_{2}$ & Oxygen delivery \\
\hline $\mathrm{EtCO}_{2}$ & End-tidal carbon dioxide tension \\
\hline LVSWI & Left ventricular stroke work index \\
\hline MAP & Mean arterial blood pressure \\
\hline MPAP & Mean pulmonary artery pressure \\
\hline $\mathrm{O}_{2} \mathrm{ER}$ & Oxygen extraction ratio \\
\hline $\mathrm{PaCO}_{2}$ & Arterial carbon dioxide tension \\
\hline $\mathrm{PaO}_{2}$ & Arterial oxygen pressure \\
\hline PAOP & Pulmonary artery occlusion pressure \\
\hline $\mathrm{PvO}_{2}$ & Venous oxygen pressure \\
\hline PVRI & Pulmonary vascular resistance index \\
\hline QS-QT & Intrapulmonary shunt fraction \\
\hline RVEDVI & Right ventricular end diastolic volume index \\
\hline RVEF & Right ventricular ejection fraction \\
\hline RVSWI & Right ventricular stroke work index \\
\hline $\mathrm{SaO}_{2}$ & Arterial oxygen percent saturation \\
\hline $\mathrm{SpO}_{2}$ & Oxygen saturation in the peripheral blood \\
\hline SVI & Stroke volume index \\
\hline $\mathrm{SVO}_{2}$ & Mixed venous oxygen saturation \\
\hline SVRI & Systemic vascular resistance index \\
\hline
\end{tabular}

onstrated significant RV dysfunction in the postoperative period after pulmonary resection..$^{8-11}$ Alterations in RV contractile function and changes in $\mathrm{RV}$ afterload are the presumed mechanisms of RV dysfunction. The aim of this study was to evaluate the acute effects of lobectomy on pulmonary hemodynamic and gas exchange variables using the RV thermodilution ejection fraction/oximetric catheter.

\section{Patients and Methods}

The study was approved by the local ethical committee of the Anesthesia Department at Mansoura University Hospital and all patients gave informed written consent. Thirty patients of either sex, with ages ranging from 20 to 50 years undergoing elective lobectomy at the Mansoura Cardiothoracic Unit were studied. The studied patients were classified into four sub-groups according to the underlying lung pathology: bronchiactesis, ${ }^{10}$ tuberculosis, ${ }^{8}$ bronchial adenoma, ${ }^{6}$ and lung abscess. ${ }^{6}$ All procedures were done by the same senior surgical staff. Patients with renal and liver dysfunction, preoperative pulmonary hypertension, arrhythmia, valvular heart disease, a history of myocardial infarction in the previous 6 months or pulmonary dysfunction were excluded from the study. A preoperative evaluation of all $\mathrm{pa}^{-}$ tients included a medical history, clinical examination including ECG and chest $\mathrm{x}$-ray, complete laboratory investigations, and an echo Doppler evaluation of the heart and valves.

On arrival of the patients to the preoperative area, a peripheral intravenous indwelling cannula was inserted. A low molecular weight hydroxyethylstarch solution $(7 \mathrm{~mL} / \mathrm{kg})$ was given before induction of general anesthesia. Premedication consisted of fentanyl $(1.0 \mu \mathrm{g} / \mathrm{kg})$ and midazolam $(0.05 \mathrm{mg} / \mathrm{kg})$ given IV 15 minutes before induction of anesthesia. Patients were connected to ECG and pulse oximetry $\left[\mathrm{SpO}_{2}\right]$ equipment. Under local lidocaine $(0.5 \%)$ anesthesia, an arterial catheter of the nondominant hand was placed $(20 \mathrm{G})$ for continuous direct arterial blood pressure recording and blood sampling for gasometry, and a pulmonary artery catheter was placed via the right internal jugular vein for hemodynamic measurements and blood sampling for gasometry. Correct placement of the pulmonary artery catheter was confirmed with characteristic pressure wave changes, and the final position of the pulmonary catheter position tip was confirmed by portable chest $\mathrm{x}$-ray. Cardiac output was measured using the thermodilution technique, by the mean value of three successive injections of $10 \mathrm{~mL}$ dextrose $5 \%$ at room temperature (Cardiac Output/SvO $\mathrm{S}_{2}$ computer, KONTRON KoloMRON TM 7250 plus coloured monitor, UK]. ECG, oxygen saturation, end-tidal carbon dioxide tension $\left[\mathrm{EtCO}_{2}\right]$ and nasopharyngeal temperature were monitored continuously [KONTRON KoloRMON TM 7250 plus anesthesia colour monitor] during the entire procedure.

Anesthesia was induced with thiopentone sodium 3-5 mg/kg IV. With loss of consciousness, positive pressure ventilation was started via facemask at a rate of $12-15$ breaths per minute. Pipecuronium $(0.07 \mathrm{mg} / \mathrm{kg})$ was given for muscle relaxation, and intubation was performed with a double-lumen, left-sided endobronchial tube (Broncho-cath TM, Mallinekrodt laboratories, Athlone, Ireland) (gauge no. 37-41). The position of the endobronchial tube was checked by inflating each lung separately while auscultating the breath sounds and by fiberoptic bronchoscopic examination by the surgeon. Anesthesia was maintained during the procedure with continuous infusion of midazolam $(0.5-1.0 \mathrm{mg} / \mathrm{kg} / \mathrm{min})$ with fentanyl $(1.0-2.0 \mu \mathrm{g} / \mathrm{kg} / \mathrm{h})$ to maintain a systolic pressure of $20 \%$ of the basal 
initial value. Pipecuronium was given in $0.03 \mathrm{mg} / \mathrm{kg}$ increments to maintain adequate surgical relaxation. Patients were mechanically ventilated with $100 \%$ $\mathrm{O}_{2}$. Ventilation was adjusted to maintain the arterial carbon dioxide tension $\left(\mathrm{PaCO}_{2}\right)$ at $36-42 \mathrm{~mm} \mathrm{Hg}$. Ringer's solution was given to maintain CVP at 8-10 $\mathrm{mm} \mathrm{Hg}$ and urine output at $1 \mathrm{~mL} / \mathrm{kg} / \mathrm{h}$. After surgery, extubation was considered if hemodynamics and respiratory parameters were stable for 20 minutes. The residual effects of neuromuscular blockade were reversed with neostigmine $(50 \mu \mathrm{g} / \mathrm{kg})$ and atropine sulfate $(20 \mu \mathrm{g} / \mathrm{kg})$.

The surgical procedure was standard posterolateral thoracotomy. After freeing the pleural adhesions, a hilar dissection was carried out. The pulmonary arteries and veins were classically dissected, double ligated with silk 2/0 ligatures and divided. The bronchial stump was closed with a single row of interrupted mattress proline 3/0 sutures. After hemostasis, two pleural drains were inserted and finally, the thoracotomy was closed anatomically in layers.

Hemodynamic measurements included heart rate (HR), mean arterial blood pressure (MAP), central venous pressure (CVP), mean pulmonary artery pressure (MPAP) and pulmonary artery occlusion pressure (PAOP), coronary oxygen persufflation (COP), cardiac index (CI), stroke volume index (SVI), right ventricular end diastolic volume (RVEDV) and right ventricular ejection fraction (RVEF). Systemic vascular resistance index (SVRI), pulmonary vascular resistance index (PVRI), left ventricular stroke work index (LVSWI) and right ventricular stroke work index (RVSWI) were calculated.

Gas exchange measurements included end-tidal carbon dioxide tension $\left(\mathrm{EtCO}_{2}\right)$, oxygen saturation in the peripheral blood $\left(\mathrm{SpO}_{2}\right)$, and mixed venous oxygen saturation $\left(\mathrm{SVO}_{2}\right.$ by fiber-optic reflectance spectrophotometry). Two blood samples were withdrawn simultaneously from both the radial artery cannula (arterial sample) and the distal tip of the pulmonary catheter (mixed-venous sample) for blood gasometry. Other measurements included oxygen saturation of both arterial and mixed-venous blood $\left(\mathrm{SaO}_{2}\right.$ and $\left.\mathrm{SvO}_{2}\right)$, arterial oxygen tension of both arterial and mixed-venous blood $\left(\mathrm{PaO}_{2}\right.$ and $\mathrm{PvO}_{2}$ ), and carbon dioxide tension of arterial blood $\left(\mathrm{PaCO}_{2}\right)$. Alveolar oxygen tension $\left(\mathrm{PAO}_{2}\right)$, the oxygen content of arterial, venous and pulmonary capillaries blood $\left(\mathrm{CaO}_{2}, \mathrm{CO}_{2}, \mathrm{CcO}_{2}\right)$, shunt fraction (Qs-Qt), arterial-end tidal carbon dioxide tension $(\mathrm{a}-\mathrm{EtCO})_{2}$, and arterial-alveolar oxygen tension ratio $\left(\mathrm{a} / \mathrm{A} \mathrm{PO}_{2}\right)$, the oxygen delivery $\left(\mathrm{DO}_{2}\right)$, oxygen uptake $\left(\mathrm{VO}_{2}\right)$, and oxygen extraction ratio $\left(\mathrm{O}_{2} \mathrm{ER}\right)$ were calculated. The hemodynamic and gas exchange parameters were recorded at preinduction (baseline), 15 minutes postinduction, and 2 hours postoperatively in the ICU.

Data are presented as mean $\pm \mathrm{SD}$. Distribution of raw data was done by Shapiro-Wilk's W test. Oneway analysis of variance with one repeated measures factor was used to compare perioperative changes in hemodynamic and gas exchange variables. For $\mathrm{F}$ value $<0.05$, multiple means were compared by Tukey's post hoc test. $P<0.05$ was considered significant.

\section{Results}

Age, sex, weight, height, and body surface area (BSA) showed no significant changes. Table 1 shows HR, MAP, and hemodynamic changes before induction of anesthesia (baseline values), 15 minutes after induction of anesthesia, and 2 hours postoperatively in the ICU. Perioperative hemoglobin concentration showed no significant changes. HR and MAP did not change significantly during the perioperative period. CVP showed no significant changes during the perioperative period.

Lobectomy was associated with significant hemodynamic changes. SVI and LVSWI significantly decreased (Table 1). RVEF showed a significant decrease after resection. MPAP, PAOP, COP, CI, SVRI, PVRI, RVSWI, and RVEDVI showed no significant changes during the perioperative period.

Table 1. Hemodynamic variables (data are in mean $\pm S D$ ).

\begin{tabular}{|c|c|c|c|}
\hline & Baseline & $\begin{array}{l}\text { Postinduction } \\
\text { (15 minutes after } \\
\text { induction) }\end{array}$ & $\begin{array}{l}\text { Postresection } \\
\text { ( } 2 \text { hours postop) }\end{array}$ \\
\hline $\mathrm{HR}(\mathrm{Bpm})$ & $89 \pm 13.97$ & $86 \pm 10.35$ & $92 \pm 14.28$ \\
\hline $\mathrm{MAP}(\mathrm{mm} \mathrm{Hg})$ & $92 \pm 14.57$ & $91 \pm 10.93$ & $88 \pm 12.57$ \\
\hline CVP (mm Hg) & $4 \pm 2.75$ & $6 \pm 4.04$ & $5 \pm 3.41$ \\
\hline MPAP (mm Hg) & $18 \pm 4.97$ & $21 \pm 5.44$ & $19 \pm 5.91$ \\
\hline $\mathrm{PAOP}(\mathrm{mm} \mathrm{Hg})$ & $10 \pm 4.96$ & $12 \pm 6.26$ & $13 \pm 5.37$ \\
\hline $\mathrm{COP}(\mathrm{L} / \mathrm{min})$ & $6.8 \pm 1.51$ & $5.7 \pm 1.98$ & $5.5 \pm 1.53$ \\
\hline $\mathrm{Cl}\left(\mathrm{L} / \mathrm{min} / \mathrm{m}^{2}\right)$ & $3.8 \pm 0.82$ & $3.2 \pm 0.96$ & $3.1 \pm 0.79$ \\
\hline SVI (mL.beat.m²) & $47 \pm 8.75$ & $40 \pm 14.21$ & $35 \pm 10.57^{*}$ \\
\hline SVRI (dyne.sec. $\mathrm{m}^{2} / \mathrm{cm}^{5}$ ) & $1878 \pm 445.87$ & $2261 \pm 898.10$ & $2333 \pm 586.32$ \\
\hline PVRI (dyne.sec.m²/cm5) & $155 \pm 52.87$ & $188 \pm 69.06$ & $160 \pm 50.97$ \\
\hline LVSWI (g.m/m²) & $53.6 \pm 8.51$ & $45.5 \pm 13.79$ & $33.9 \pm 9.89 *$ \\
\hline RVSWI (g.m/m²) & $7.6 \pm 3.18$ & $8.5 \pm 2.98$ & $6.9 \pm 3.31$ \\
\hline RVEDVI $\left(\mathrm{mL} / \mathrm{m}^{2}\right)$ & $160 \pm 38.51$ & $137 \pm 47.79$ & $141 \pm 49.10$ \\
\hline RVEF (\%) & $37 \pm 6.63$ & $34 \pm 9.14$ & $27 \pm 12.74^{*}$ \\
\hline
\end{tabular}

*Significant when compared with baseline values $(P<0.05)$ 
Table 2: Gas exchange variables (data are in mean \pm SD)

\begin{tabular}{|c|c|c|c|}
\hline & Baseline & $\begin{array}{l}\text { Postinduction } \\
\text { (15 minutes after } \\
\text { induction) }\end{array}$ & $\begin{array}{l}\text { Postresection } \\
\text { ( } 2 \text { hours postop) }\end{array}$ \\
\hline $\mathrm{SaO}_{2}(\%)$ & $97 \pm 1.92$ & $98 \pm 0.89$ & $98 \pm 0.77$ \\
\hline Continuous $\mathrm{SvO}_{2}(\%)$ & $78 \pm 4.77$ & $81 \pm 4.56$ & $85 \pm 5.79 *$ \\
\hline $\mathrm{SvO}_{2}(\%)$ & $77 \pm 5.47$ & $80 \pm 4.51$ & $84 \pm 6.45^{*}$ \\
\hline $\mathrm{a} / \mathrm{A} \mathrm{PO}_{2}(\%)$ & $37.6 \pm 10.92$ & $44.4 \pm 18.33$ & $47.1 \pm 15.34$ \\
\hline QS-0T (\%) & $25.28 \pm 8.44$ & $29.07 \pm 12.24$ & $29.97 \pm 11.74$ \\
\hline $\mathrm{DO}_{2}\left(\mathrm{~mL} / \mathrm{min} / \mathrm{m}^{2}\right)$ & $705 \pm 135$ & $711 \pm 225$ & $720 \pm 336$ \\
\hline $\mathrm{VO}_{2}\left(\mathrm{~mL} / \mathrm{min} / \mathrm{m}^{2}\right)$ & $157 \pm 44$ & $144 \pm 65$ & $118 \pm 34^{*}$ \\
\hline $\mathrm{O}_{2} \mathrm{ER}(\%)$ & $21 \pm 6.6$ & $18 \pm 6$ & $18 \pm 5$ \\
\hline
\end{tabular}

${ }^{*}$ Significant when compared with baseline values $(P<0.05)$

Continuous $\mathrm{SvO}_{2}$ and $\mathrm{SvO}_{2}$ showed a significant increase after lung resection when compared with preinduction values, while $\mathrm{VO}_{2}$ significantly decreased from $157 \pm 44$ (preinduction values) to $118 \pm 34$ (post-resection values) $\mathrm{mL} \cdot \mathrm{min}^{-1} \cdot \mathrm{m}^{-2}$ (Table 2). $\mathrm{SaO}_{2}$, a/A $\mathrm{PO}_{2}$, QS-QT, $\mathrm{DO}_{2}$, and $\mathrm{O}_{2} \mathrm{ER}$ showed no significant changes during the perioperative period.

Statistically significant changes occurred in some hemodynamic and gas exchange variables between baseline and post-resection values when the patients were classified into subgroups according to the underlying lung pathology (Table 3). However, other parameters showed no significant changes.

\section{Discussion}

Stroke work is the product of two variables, the pressure generated in the ventricle and the volume output. The advantages of using stroke work instead of cardiac output or stroke volume is that it includes $H R$, preload, and afterload, the major variables af- fecting cardiac function. ${ }^{12}$ In our patients, 2 hours after lung resection, LVSWI significantly decreased. HR showed no significant changes perioperatively. Preload represented by CVP appeared normal during the perioperative period in relation to the normal range. PAOP also showed no significant changes. On the other hand, SVI was decreased after lobectomy. So the marked decrease in LVSWI post-resection in our study was due to a parallel decrease in SVI after lung resection.

In this study, 2 hours after lobectomy, there was significant RV dysfunction as measured by reduced RVEF. This is in agreement with previous studies. $^{8-11,13}$ The present study demonstrated that RVEF declines while RVEDVI remains stable in the early postoperative period with a significant decrease in SVI. This is in agreement with Reed et al. ${ }^{10}$ who found that RVEDV remained stable in the early postoperative hours and increased significantly on postoperative day 1 and 2. In our study, PAP and PVRI remained unchanged from baseline values. We speculated that afterload is not the causative factor of RV dysfunction in the early postoperative period and that alteration in RV contractility may be the causal factor. Other studies contradict this finding and claim that afterload alteration is the major determinant of RV dysfunction. ${ }^{10,14}$ Reed et al., ${ }^{9}$ suggest that RV dysfunction that occurs during the early postoperative period after lung resection are not solely due to changes in RV afterload or changes in contractile state.

In the present study, the left heart decompensation in the early postoperative period after lobectomy as demonstrated by a significant reduction in SVI and LVSWI may be due to a consequence of RV dysfunction, either by decreasing left ventricular preload or by shifting the interventricular septum,

Table 3. Hemodynamic and gas exchanges variables according to the underlying lung pathology (data are in mean $\pm S D$ ).

\begin{tabular}{|c|c|c|c|c|c|c|c|c|}
\hline & \multicolumn{2}{|c|}{ Bronchiectasis } & \multicolumn{2}{|c|}{ Tuberculosis } & \multicolumn{2}{|c|}{ Bronchial adenoma } & \multicolumn{2}{|c|}{ Lung abscess } \\
\hline & Baseline & $\begin{array}{l}\text { Post } \\
\text { resection }\end{array}$ & Baseline & $\begin{array}{l}\text { Post } \\
\text { resection }\end{array}$ & Baseline & $\begin{array}{l}\text { Post } \\
\text { resection }\end{array}$ & Baseline & $\begin{array}{c}\text { Post } \\
\text { resection }\end{array}$ \\
\hline SVI (mL/beat/m²) & $51 \pm 7.83$ & $27 \pm 6.19^{*}$ & $41 \pm 7.63$ & $32 \pm 3.71$ & $44 \pm 8.76$ & $37 \pm 10.75$ & $49 \pm 9.81$ & $43 \pm 15.87$ \\
\hline LVSWI (g.m/m²) & $49.2 \pm 5.43$ & $28.3 \pm 9.82^{*}$ & $53.6 \pm 11.71$ & $31.4 \pm 6.62^{*}$ & $57.3 \pm 10.55$ & $34.3 \pm 8.83^{*}$ & $55.9 \pm 8.15$ & $39.2 \pm 16.73$ \\
\hline RVEF (\%) & $36 \pm 6.88$ & $21 \pm 4.51^{*}$ & $36 \pm 5.25$ & $22 \pm 9.74^{*}$ & $36 \pm 8.96$ & $24 \pm 12.70^{*}$ & $39 \pm 9.07$ & $41 \pm 12.70$ \\
\hline $\mathrm{VO}_{2}\left(\mathrm{~mL} / \mathrm{min} / \mathrm{m}^{2}\right)$ & $168 \pm 26.01$ & $122 \pm 37.14^{*}$ & $152 \pm 70.82$ & $100 \pm 38.53$ & $159 \pm 63.59$ & $130 \pm 40.55$ & $154 \pm 12.86$ & $123 \pm 23.51^{*}$ \\
\hline $\mathrm{SvO}_{2}(\%)$ & $76.5 \pm 2.67$ & $80.3 \pm 7.18$ & $76.3 \pm 5.67$ & $85.2 \pm 6.99^{*}$ & $76.2 \pm 3.31$ & $86.3 \pm 7.44^{*}$ & $74.4 \pm 6.50$ & $85.1 \pm 7.44^{*}$ \\
\hline Continuous $\mathrm{SvO}_{2}(\%)$ & $77 \pm 1.14$ & $82 \pm 7.26$ & $78 \pm 7.33$ & $85 \pm 7.14^{*}$ & $78 \pm 1.14$ & $85 \pm 6.22^{*}$ & $78 \pm 7.00$ & $84 \pm 4.58^{*}$ \\
\hline
\end{tabular}

*Significant when compared with baseline values $[P<0.05)$ 
resulting in a decreased left ventricular volume. ${ }^{15}$

In the present study, lobectomy was associated with minor deterioration of the gas exchange variables. We demonstrated no significant change in arterial oxygen saturation, alveolar-arterial $\mathrm{PO}_{2}$, and circulatory shunt, 2 hours after lobectomy. This is in accordance with Sekine et $\mathrm{al}^{16}$ who found that lobectomy was associated with good maintenance of gas exchange for only 6 to 12 hours after resection and then deteriorated because of peripheral atelectasis.

Few researchers have studied the changes in oxygen uptake after lung resection. ${ }^{17-19}$ We found a fall in the oxygen uptake $\left(\mathrm{VO}_{2}\right)$ of $25 \%, 2$ hours after lobectomy, which correlated with the simultaneous increase in mixed-venous oxygen saturation $\left(\mathrm{SvO}_{2}\right)$. Markos et $\mathrm{al}^{17}$ found a fall in maximal oxygen uptake of 27\%, 3 months after pneumonectomy, and 13\% after lobectomy. Corris et $\mathrm{al}^{18}$ found a fall in maximal oxygen uptake of 23\%, 4 months after pneumonectomy. Larsen et $\mathrm{al}^{19}$ found that pneumonectomy causes a decrease in pulmonary volumes to about $75 \%$ of the preoperative values, partly compensated by better oxygen uptake, which postoperatively was about $85 \%$ of the preoperative values.

From this study, we can conclude that in the acute post-resection period (up to 2 hours postoperatively) there is right and left ventricular dysfunction with good maintenance of gas exchange.

\section{References}

1. Keagy BA, Lores ME,Starek PJ, Murray GF, Lucas $\mathrm{CL}$, Wilcox BR. Elective pulmonary lobectomy: factors associated with morbidity and operative mortality. Ann Thorac Surg. 1985;40:349-52

2. Kohman LJ, Meyer JA, Ikins PM, Oates RP. Random versus predictable risks of mortality after thoracotomy for lung cancer. J Thorac Cardiovasc Surg. 1986;91:551-4

3. Wahi R, McMurtrey MJ, DeCaro LF, Mountain CF, Ali MK, Smith TI. Determinants of perioperative morbidity and mortality after pneumonectomy. Ann Thorac Surg. 1989;48:33-7

4. Keagy BA, Schorlemmer GR, Murray GF Starek PJ, Wilcox BR. Correlation of preoperative pulmonary function testing with clinical course in patients after pneumonectomy. Ann Thorac Surg. 1983;36:253-7

5. Hoffman MJ, Greenfield LJ, Sugarman HJ, Tatum JL. Unsuspected right ventricular dysfunction in shock and sepsis. Ann Surg. 1983;197:307-17.

6. Martyn JAJ, Snider MJ, Szyfelbein SK, Burke $\mathrm{JF}$, Laver MB. Right ventricular dysfunction in acute thermal injury. Ann Surg. 1980;191:330-5.

7. Rabinovitch MA, Elstein J, Chiu RC-J, Rose CP Arzoumanian A, Burgess JH. Selective right ven- tricular dysfunction after coronary artery bypass grafting. J Thorac Cardiovasc Surg. 1983;86:444-6.

8. Reed C.E., Spinale F.G., Crawford F.A. Effect of pulmonary resection on right ventricular function. Ann Thorac Surg. 1992;35:578-582.

9. Reed C.E., Dorman B.H., Spinale F.G. Mechanisms of right ventricular dysfunction after pulmonary resection. Ann Thorac Surg. 1996;62:225-232. 10. Reed C.E., Dorman B.H., Spinale F.G. Assessment of right ventricular contractile performance after pulmonary resection. Ann Thorac Surg. 1993;56:426-432.

11. Okada M., Ota T, Okada M., Matsuda H., Okada K., Ishii N. Right ventricular dysfunction after major pulmonary resection. J Thorac Cardiovasc Surg. 1994;108:503-511.

12. Barash PG, Kopriva GJ. Cardiac pump function and how to monitor it. In Thomas SJ (ed): Manual of cardiac anesthesia, New York, Churchill Livingstone, 1984;1-17

13. Kowalewski J, Brocki M, Dryjanski T, Kapron K, Barcikowski S. Right ventricular morphology and function after pulmonary resection. Eur J Cardiothorac Surg. 1999;15(4):444-8

14. Amar D, Burt ME, Roistacher N, Reinsel RA,
Ginsberg RJ, Wilson RS. Value of perioperative doppler echocardiography in patients undergoing major lung resection. Ann Thorac Surg. 1996;61:516-520

15. Amar D, Roistacher N, Burt ME, Reinsel RA, Ginsberg RJ, Wilson RS. Clinical and echocardiographic correlates of symptomatic tachydysrhythmias after noncardiac thoracic surgery. Chest. 1995;108:349-345

16. Sekine $Y$, Miyata $K$, Yamada $H$, Yasukawa T, Yoshida S, Saitoh Y, Fujisawa T. Evaluation of pulmonary gas exchange after lobectomy and simple thoracotomy. Scand Cardiovasc J. 2000;34(3):339-44 17. Markos J, Mullan BP, Hillman DR, et al. Preoperative assessment as a predictor of mortality and morbidity after lung resection. Am Rev Respir Dis. 1989;139:902-10

18. Corris PA, Ellis DA, Hawkins T, Gibson GJ. Use of radionuclide scanning in the preoperative estimation of pulmonary function after pneumonectomy. Thorax. 1987;42:285-91

19. Larsen KR, Svendsen UG, Milman N, Brenoe $\mathrm{J}$, Petersen BN. Cardiopulmonary function at rest and during exercise after resection for bronchial carcinoma. Ann Thorac Surg. 1997;64:960-4 